\title{
Therapeutic effect and adverse reaction of sorafenib in the treatment of advanced renal cancer
}

\author{
JUHUI QIU ${ }^{1}$, DONGJIAN LIU ${ }^{2}$, ZAICHUN YAN $^{2}$, WEI JIANG ${ }^{2}$, \\ QINGLEI ZHANG ${ }^{3}, \mathrm{NING} \mathrm{LI}^{4}$, WENTAO DENG ${ }^{2}$ and KEJIA DING ${ }^{1}$ \\ ${ }^{1}$ Department of Urology, Shandong Provincial Hospital Affiliated to Shandong University, Jinan, Shandong 250021; \\ ${ }^{2}$ Department of Urology, Dongying People's Hospital, Dongying, Shandong 257091; ${ }^{3}$ Department of Urology, \\ Tengzhou Central People's Hospital, Zaozhuang, Shandong 277500; ${ }^{4}$ Department of Urology, \\ Guangrao County Hospital of TCM, Dongying, Shandong 257300, P.R. China
}

Received May 17, 2018; Accepted November 15, 2018

DOI: $10.3892 / \mathrm{ol} .2018 .9776$

\begin{abstract}
Efficacy and safety of sorafenib in patients with advanced renal cancer were evaluated. Seventy-four patients with advanced renal cancer treated with sorafenib + interferon from January 2010 to August 2013 were included as the observation group. Another 53 renal cancer patients treated with interferon alone were included in the control group. Clinical data of those patients were retrospectively analyzed. Treatment plan: initial dose was $400 \mathrm{mg}$, twice a day. Additionally, patients in the interferon group were treated with another 300 MU every other day. Efficacy was evaluated according to RECIST criteria, and progression-free survival (PFS), overall survival (OS), and incidence of adverse reactions were recorded. In the observation group, a median OS was 15.3 months (range, 9-60 months), and a median PFS was 8.2 months (range, 2-36 months). There were 4 cases of complete remission (CR) (5.41\%), 16 cases of partial remission (PR) (21.62\%), 42 cases of stable disease (SD) $(56.76 \%), 12$ cases of disease progression $(16.22 \%)$, and disease control rate (DCR) was $83.78 \%$ (62 cases). In the control group, median OS time was 12.5 months (range, 8-60 months), and the median PFS time was 9.3 months (range, 2-40 months). There were 2 cases of CR (3.77\%), 11 cases of PR (20.75\%), 20 cases of SD (37.74\%), 20 cases of disease progression (37.74\%), and DCR was $62.26 \%$ (33 cases). Disease control rate in the observation group was significantly higher than that in the control group $(\mathrm{P}<0.05)$. Main adverse events in the groups were skin reaction, fever, diarrhea, fatigue, rash, loss of appetite, hypertension, hair loss and liver function abnormality. Sorafenib-based targeted therapy for the treatment of advanced renal cancer has a higher rate of disease control, and the adverse reactions are controllable and tolerable.
\end{abstract}

Correspondence to: Dr Kejia Ding, Department of Urology, Shandong Provincial Hospital Affiliated to Shandong University, 324 Jingwuweiqi Road, Jinan, Shandong 250021, P.R. China

E-mail:dq7q3p@163.com

Key words: sorafenib, advanced renal cancer, targeted therapy, efficacy, adverse reactions

\section{Introduction}

Renal cancer is one of the most common clinical urological tumors, accounting for $4 \%$ of adult malignancies and 80-90\% of adult renal malignant diseases. In China, renal cancer affects 453,000 people and causes 396,000 deaths every year (1). Incidence of renal cancer is higher in developed countries than in developing countries, and is higher in males than in females (2). Main factors leading to renal cancer include tobacco consumption, alcohol abuse and obesity (3). Renal cancer at early stages has no obvious symptoms, and patients showing hematuria, pain, and mass are usually in advanced stages with distant tumor metastasis (4). At present, surgical treatment is still the main treatment for renal cancer. However, recurrence and metastasis still occurs in 32\% patients with renal cancer after operation (5). Survival period of patients in advanced stages is 6-12 months, and the 5-year survival rate is $<10 \%$. Traditional treatment methods such as radiotherapy, chemotherapy, and interferon are effective for only $10-30 \%$ patients (6).

In recent years, a large number of clinically open phase III trials have demonstrated that targeted drugs are superior to radiochemotherapy and interferon in the treatment of advanced renal cancer, and have good tolerance and minimal adverse reactions (7). Cancer treatment has entered the age of targeted therapy. As a kinase inhibitor, sorafenib inhibits many kinds of extracellular and intracellular kinases and has dual antitumor and anti-angiogenic effects (8). It can inhibit MRK and RAF signaling pathways as well as VECFR, PDGFR and tumor neovascularization, and has become the first-line targeted drug for the treatment of advanced renal cancer (9).

In this study, clinical data of patients with advanced renal cancer treated with sorafenib in Shandong Provincial Hospital Affiliated to Shandong University (Jinan, China) were analyzed, and treatment efficacy, adverse events and prognosis were analyzed as well. Our study provided references for the treatment of advanced renal cancer.

\section{Patients and methods}

Clinical data. A total of 74 patients (41 males and 33 females, median age 56.5 years) with advanced renal cancer treated with 
sorafenib + interferon from January 2010 to August 2013 were included as the observation group. Another 53 renal cancer patients (29 males and 24 females, median age 58.2 years) treated with interferon alone were included as the control group. Clinical data of the patients were retrospectively analyzed.

Inclusion and exclusion criteria. Inclusion criteria: patients with AJCC stage VI renal cancer; patients with measurable tumor lesions $\geq 2.0 \mathrm{~cm}$ in diameter; patients without serious viral and bacterial infections; patients received no systemic renal cancer treatment. Exclusion criteria: patients with other tumors; patients with a history of severe allergies; patients with major organ dysfunction; patients who had received organ transplantation; patients with autoimmune system disorders; patients with severe mental illness. The study was approved by the Ethics Committee of Shandong Provincial Hospital Affiliated to Shandong University. All the patients or their families signed an informed consent.

Treatment. Sorafenib was purchased from Bayer AG, [Leverkusen, Germany (HQ)]. All patients were treated with sorafenib in fasting state with a dose of $400 \mathrm{mg}$, twice a day. Besides that, patients in the interferon group were treated with another $300 \mathrm{MU}$ every other day through subcutaneous injection, 4 weeks for 1 treatment cycle. Patients were not allowed to eat high-fat foods within $3 \mathrm{~h}$ after taking the drug. If serious adverse reactions occurred during medication, the dose was reduced. The normal dose was reused after recovery. Treatment efficacy, no disease progression time and adverse reactions were recorded. Blood pressure was measured every other day. Related imaging examinations, blood routine tests, electrocardiogram, liver and kidney function tests as well as adverse reactions were evaluated every 4 weeks to evaluate the safety of medication.

Efficacy evaluation and adverse reactions. Efficacy evaluation was performed according to Revised Evaluation Standards for Efficacy of Solid Tumors (10). Patients were divided into complete remission (CR), partial remission (PR), stable disease (SD), progression of disease (PD), objective response rate (RR) was $\mathrm{CR}+\mathrm{PR}$ and disease control rate (DCR) was $\mathrm{CR}+\mathrm{PR}+\mathrm{SD}$. Adverse reactions were evaluated according to the National Cancer Institute (NCI-CTC) grading standard (version 4.03) (11).

Follow-up. A prospective follow-up was performed mainly through telephone and out-patient visit every 3 months for 5 years. The cause and time of death were recorded.

Statistical analysis. The data of this study were analyzed using SPSS 17.0 (Beijing Xinmeijiahong Technology Co., Ltd. Beijing, China) software. Measurement data was expressed as mean \pm standard deviation and comparisons between the two groups were performed by t-test. Enumeration data were expressed as (\%) and compared using $\chi^{2}$ test. Survival analysis was performed using the Kaplan-Meier method and log-rank test. $\mathrm{P}<0.05$ was considered to indicate a statistically significant difference.

\section{Results}

Comparison of general data. No significant differences in sex, age, ECOC score, tumor size, and TNM stages were found between the two groups $(\mathrm{P}>0.05)$ (Table I).
Table I. Comparison of general data (n, \%).

\begin{tabular}{|c|c|c|c|c|}
\hline Indexes & $\begin{array}{l}\text { Observation } \\
\quad(\mathrm{n}=74)\end{array}$ & $\begin{array}{c}\text { Control } \\
(\mathrm{n}=53)\end{array}$ & $\chi^{2}$ & P-value \\
\hline Sex & & & 0.006 & 0.956 \\
\hline Male & $41(55.41)$ & $29(54.72)$ & & \\
\hline Female & 33 (44.59) & $24(45.28)$ & & \\
\hline Age & & & 0.164 & 0.592 \\
\hline$\geq 55$ & $38(51.35)$ & $30(56.60)$ & & \\
\hline$<55$ & $36(48.65)$ & $23(43.40)$ & & \\
\hline ECOC score & & & 0.042 & 0.855 \\
\hline 0 & $46(62.16)$ & $32(60.38)$ & & \\
\hline 1 & $28(37.84)$ & $21(39.62)$ & & \\
\hline Tumor size & & & 0.193 & 0.586 \\
\hline$\geq 5 \mathrm{~cm}$ & $42(56.76)$ & $33(62.26)$ & & \\
\hline$<5 \mathrm{~cm}$ & $32(43.24)$ & $20(37.74)$ & & \\
\hline \multicolumn{5}{|l|}{ TNM stage } \\
\hline \multicolumn{5}{|l|}{ T stage } \\
\hline $\mathrm{T} 1$ & $9(12.16)$ & $5(9.43)$ & & \\
\hline $\mathrm{T} 2$ & $13(17.57)$ & $7(13.21)$ & & \\
\hline $\mathrm{T} 3$ & $17(22.97)$ & $13(24.53)$ & & \\
\hline $\mathrm{T} 4$ & $35(47.30)$ & $28(52.83)$ & & \\
\hline $\mathrm{N}$ stage & & & 0.014 & 0.528 \\
\hline NO & $23(31.08)$ & $17(32.08)$ & & \\
\hline N1 & $51(68.92)$ & $36(67.92)$ & & \\
\hline M stage & & & 0.228 & 0.561 \\
\hline M0 & $21(28.38)$ & $18(33.96)$ & & \\
\hline M1 & $53(71.62)$ & $35(66.04)$ & & \\
\hline
\end{tabular}

Evaluation of treatment efficacy. The observation group included 4 cases of CR (5.41\%), 16 cases of PR (21.62\%), 42 cases of SD (56.76\%), 12 cases of PD (16.22\%), and 62 cases of DCR (83.78\%). In the control group, there were 2 cases of CR (3.77\%), 11 cases of PR (20.75\%), 20 cases of SD (37.74\%), 12 cases of PD (37.74\%), and 33 cases of DCR (62.26\%). DCR in the observation group was significantly higher than that in the control group $(\mathrm{P}<0.05)$ (Table II).

Survival analysis. In the observation group, Kaplan-Meier survival analysis showed a median overall survival (OS) of 15.3 months (range, 9-60 months), and a median progression-free survival (PFS) of 8.2 months (range, 2-36 months). The 1-year survival rate was $87.84 \%$, the 3 -year survival rate was $68.92 \%$, and the 5-year survival rate was $36.49 \%$. In the control group, the median OS time was 12.5 months (range, 8-60 months), and the median PFS time was 9.3 months (range, 2-40 months). The 1-year survival rate was $73.56 \%$, the 3-year survival rate was $47.17 \%$, and the 5 -year survival rate was $18.87 \%$. The 5 -year survival rate in the observation group was significantly higher than that in the control group $(\mathrm{P}<0.05)$ (Fig. 1).

Adverse reactions. Adverse reactions in the two groups mainly included hand-foot skin reaction, fever, diarrhea, fatigue, rash, loss of appetite, hypertension, hair loss, liver function abnormality, and there was no statistical significance in incidence of adverse reactions between the two groups $(\mathrm{P}>0.05)$ (Table III). 
Table II. Evaluation of treatment efficacy $(n, \%)$.

\begin{tabular}{|c|c|c|c|c|c|c|c|}
\hline Items & $\mathrm{n}$ & $\mathrm{CR}$ & PR & SD & PD & RR & DCR \\
\hline Observation & 74 & $4(5.41)$ & $16(21.62)$ & $42(56.76)$ & $12(16.22)$ & $20(27.03)$ & $62(83.78)$ \\
\hline Control & 53 & $2(3.77)$ & $11(20.75)$ & $20(37.74)$ & $20(37.74)$ & $13(24.53)$ & $33(62.26)$ \\
\hline$\chi^{2}$ & & 0.183 & 0.014 & 3.743 & 6.489 & 0.022 & 6.489 \\
\hline $\mathrm{P}$-value & & 0.508 & 0.543 & 0.047 & 0.007 & 0.526 & 0.007 \\
\hline
\end{tabular}

CR, complete remission; PR, partial remission; SD, stable disease; PD, progression of disease; RR, response rate; DCR, disease control rate.

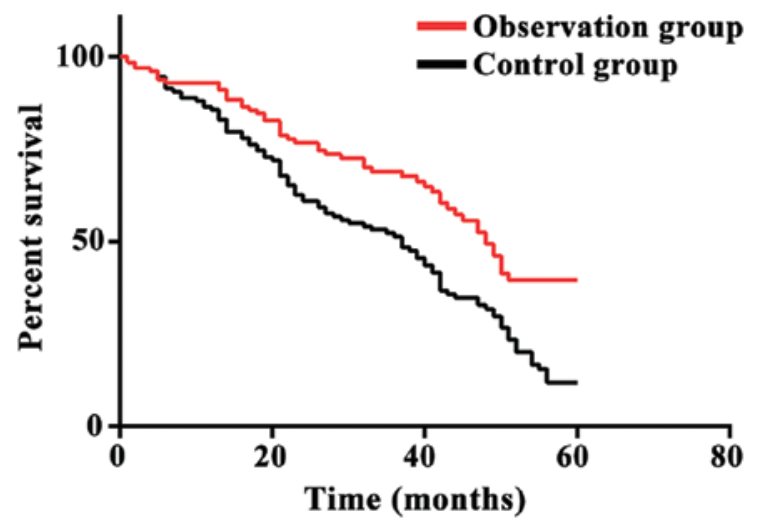

Figure 1. Comparison of the 5-year survival rate between the two groups of patients. The 5-year survival rate of the observation group was significantly higher than that of the control group $(\mathrm{P}<0.05)$.

Table III. Adverse effects of sorafenib (\%).

\begin{tabular}{lcccc}
\hline $\begin{array}{l}\text { Adverse } \\
\text { reactions }\end{array}$ & $\begin{array}{c}\text { Observation } \\
(\mathrm{n}=74)\end{array}$ & $\begin{array}{c}\text { Control } \\
(\mathrm{n}=53)\end{array}$ & $\chi^{2}$ & P-value \\
\hline $\begin{array}{l}\text { Hand-foot } \\
\text { skin reaction }\end{array}$ & $18(24.32)$ & $16(30.19)$ & 0.284 & 0.543 \\
Fever & $6(8.11)$ & $8(15.09)$ & 0.907 & 0.257 \\
Diarrhea & $15(20.27)$ & $13(24.53)$ & 0.125 & 0.665 \\
Fatigue & $11(14.86)$ & $10(18.87)$ & 0.127 & 0.631 \\
Rash & $3(4.05)$ & $5(9.43)$ & 0.740 & 0.277 \\
Loss of & $10(13.51)$ & $8(15.09)$ & 0.063 & 0.802 \\
$\begin{array}{l}\text { appetite } \\
\text { Hypertension }\end{array}$ & $10(13.51)$ & $13(24.53)$ & 1.838 & 0.160 \\
Hair loss & $4(5.41)$ & $2(3.77)$ & 0.183 & 0.508 \\
Abnormal & $5(6.76)$ & $5(9.43)$ & 0.048 & 0.741 \\
liver function & & & & \\
\hline
\end{tabular}

\section{Discussion}

Primary renal cancer is one of the most common malignancies in clinical practice. Since most of the patients are diagnosed at advanced stages, treatment outcome and prognosis are usually poor (12). Efficacy of immunotherapy, radiotherapy and chemotherapy in the treatment of renal cancer is low. In recent years, a variety of targeted drugs have also been successfully used in the treatment of renal cancer, and objective effectiveness, PFS and OS have improved significantly (13). Sorafenib is an oral small molecule multikinase inhibitor that inhibits the phosphorylation of RAF/MEK/ERK by inhibiting the activity of c-RAF and b-RAF kinases in tumor cells to inhibit the proliferation and growth of tumor cells (14). Sorafenib is the earliest targeted agent in the treatment of stage IV renal cancer. Multiple clinical studies have confirmed the value of sorafenib in the treatment of advanced renal cancer $(15,16)$.

Results of this study showed that the control group had an objective RR of $24.53 \%$, a DCR of $62.26 \%$, a median OS of 15.3 months (range, 9-60 months), and a median PFS of 8.2 months (range, 2-36 months), while the 1-year survival rate was $73.56 \%$, the 3 -year survival rate was $47.17 \%$, and the 5-year survival rate was $18.87 \%$. The observation group had an objective RR of $27.03 \%$, a DCR of $83.78 \%$, a median OS of 12.5 months (range, 8-60 months), and a median PFS of 9.3 months (range, 2-40 months), while the 1-year survival rate was $87.84 \%$, the 3 -year survival rate was $68.92 \%$, and the 5 -year survival rate was $36.49 \%$. DCR in the observation group was significantly higher than that in the control group $(\mathrm{P}<0.05)$. The 5-year survival rate in the observation group was significantly higher than that in the control group $(\mathrm{P}<0.05)$. Compared with the control group, targeted therapy can reduce the drug resistance of sorafenib and prolong the survival of patients. Targeting therapy with sorafenib can inhibit tumor growth-related signaling pathways. After cytotoxic sorafenib act on tumor cells, tumor cell apoptosis will be induced and tumor size will be reduced (17). On the other hand, SD reflects cancer cell growth inhibition and has important value in evaluation of targeted therapy (18). Consistent with related reports by Yang et al (19), it was pointed out that sorafenib can directly induce tumor cell apoptosis, indicating that sorafenib can delay SD and prolong the OS of patients.

Consistent with the findings reported by Galluzzi et al (20), it was confirmed that targeted treatment with sorafenib can effectively prolong the survival of patients with renal cancer. Adverse reactions were observed in both groups and no significant differences in incidence of adverse reactions were found between the two groups $(\mathrm{P}>0.05)$. Most adverse reactions are controlled and tolerated through drug reduction, drug suspension or symptomatic treatment. Adverse reactions of Nexavar mainly include hand-foot skin reactions, skin rashes, hypertension, and vomiting, which are basically the same as reported by previous studies (21).

Sorafenib targeted therapy can be used to treat renal cancer that is not suitable for surgery or have distant metastasis. 
Sorafenib can effectively prolong a patient's survival and efficacy is stable. This is a retrospective study with a small sample size, and regional differences cannot be avoided. Our future studies will attempt to solve these problems.

In conclusion, treatment with sorafenib achieved longer OS and PFS in patients with advanced renal cancer. DCR of sorafenib is high and adverse reactions can be controlled and tolerated.

\section{Acknowledgements}

Not applicable.

\section{Funding}

No funding was received.

\section{Availability of data and materials}

The datasets used and/or analyzed during the present study are available from the corresponding author on reasonable request.

\section{Authors' contributions}

JQ drafted the manuscript. JQ and DL were mainly devoted to collecting and interpreting the general data. ZY, WJ and QZ helped with efficacy evaluation and adverse reactions. NL, WD and KD were responsible for follow-up. All authors read and approved the final study.

\section{Ethics approval and consent to participate}

The study was approved by the Ethics Committee of Shandong Provincial Hospital Affiliated to Shandong University (Jinan, China). Signed informed consents were obtained from the patients or guardians.

\section{Patient consent for publication}

Not applicable.

\section{Competing interests}

The authors declare that they have no competing interests.

\section{References}

1. Ferlay J, Soerjomataram I, Dikshit R, Eser S, Mathers C, Rebelo M, Parkin DM, Forman D and Bray F: Cancer incidence and mortality worldwide: Sources, methods and major patterns in GLOBOCAN 2012. Int J Cancer 136: E359-E386, 2015.

2. Torre LA, Siegel RL, Ward EM and Jemal A: Global cancer incidence and mortality rates and trends - An update. Cancer Epidemiol Biomarkers Prev 25: 16-27, 2016.

3. Goday A, Barneto I, García-Almeida JM, Blasco A, Lecube A, Grávalos C, Martínez de Icaya P, de las Peñas R, Monereo S, Vázquez L, et al: Obesity as a risk factor in cancer: A national consensus of the Spanish Society for the Study of Obesity and the Spanish Society of Medical Oncology. Clin Transl Oncol 17: 763-771, 2015.

4. Eble JN and Delahunt B: Emerging entities in renal cell neoplasia: Thyroid-like follicular renal cell carcinoma and multifocal oncocytoma-like tumours associated with oncocytosis. Pathology 50: 24-36, 2018.
5. Santoni M, Conti A, Partelli S, Porta C, Sternberg CN, Procopio G, Bracarda S, Basso U, De Giorgi U, Derosa L, et al: Surgical resection does not improve survival in patients with renal metastases to the pancreas in the era of tyrosine kinase inhibitors. Ann Surg Oncol 22: 2094-2100, 2015.

6. Pérez-Herrero E and Fernández-Medarde A: Advanced targeted therapies in cancer: Drug nanocarriers, the future of chemotherapy. Eur J Pharm Biopharm 93: 52-79, 2015.

7. Choueiri TK, Halabi S, Sanford BL, Hahn O, Michaelson MD, Walsh MK, Feldman DR, Olencki T, Picus J, Small EJ, et al: Cabozantinib versus sunitinib as initial targeted therapy for patients with metastatic renal cell carcinoma of poor or intermediate risk: The alliance A031203 CABOSUN trial. J Clin Oncol 35: 591-597, 2017.

8. Jiao Y, Xin BT,Zhang Y,Wu J, Lu X, Zheng Y, Tang W and Zhou X: Design, synthesis and evaluation of novel 2-(1H-imidazol-2-yl) pyridine Sorafenib derivatives as potential BRAF inhibitors and anti-tumor agents. Eur J Med Chem 90: 170-183, 2015.

9. Zhai B, Jiang X, He C, Zhao D, Ma L, Xu L, Jiang H and Sun X: Arsenic trioxide potentiates the anti-cancer activities of sorafenib against hepatocellular carcinoma by inhibiting Akt activation. Tumour Biol 36: 2323-2334, 2015.

10. Flaherty KT, Manola JB, Pins M, McDermott DF, Atkins MB, Dutcher JJ, George DJ, Margolin KA and DiPaola RS: BEST: A randomized phase II study of vascular endothelial growth factor, RAF kinase, and mammalian target of rapamycin combination targeted therapy with bevacizumab, sorafenib, and temsirolimus in advanced renal cell carcinoma - A trial of the ECOG-ACRIN cancer research group (E2804). J Clin Oncol 33: 2384-2391, 2015.

11. Ljungberg B, Bensalah K, Canfield S, Dabestani S, Hofmann F, Hora M, Kuczyk MA, Lam T, Marconi L, Merseburger AS, et al: EAU guidelines on renal cell carcinoma: 2014 update. Eur Urol 67: 913-924, 2015.

12. Shahabi V,Postow MA, Tuck D and Wolchok JD: Immune-priming of the tumor microenvironment by radiotherapy: Rationale for combination with immunotherapy to improve anticancer efficacy. Am J Clin Oncol 38: 90-97, 2015.

13. Lin HH, Feng WC, Lu LC, Shao YY, Hsu CH and Cheng AL: Inhibition of the Wnt/ $\beta$-catenin signaling pathway improves the anti-tumor effects of sorafenib against hepatocellular carcinoma. Cancer Lett 381: 58-66, 2016.

14. Raman R and Vaena D: Immunotherapy in metastatic renal cell carcinoma: A comprehensive review. BioMed Res Int 2015: 367354, 2015

15. He C, Dong X, Zhai B, Jiang X, Dong D, Li B, Jiang H, Xu S and Sun X: MiR-21 mediates sorafenib resistance of hepatocellular carcinoma cells by inhibiting autophagy via the PTEN/Akt pathway. Oncotarget 6: 28867-28881, 2015.

16. Ma X, Shen D, Li H, Zhang Y, Lv X, Huang Q, Gao Y, Li X, Gu L, Xiu S, et al: MicroRNA-185 inhibits cell proliferation and induces cell apoptosis by targeting VEGFA directly in von Hippel-Lindau-inactivated clear cell renal cell carcinoma. Urol Oncol 33: 169.e1-169.e11, 2015.

17. Bil J, Zapala L, Nowis D, Jakobisiak M and Golab J: Statins potentiate cytostatic/cytotoxic activity of sorafenib but not sunitinib against tumor cell lines in vitro. Cancer Lett 288: 57-67, 2010.

18. Takahashi Y, Mai M, Taguchi T, Urushizaki I and Nishioka K: Prolonged stable disease effects survival in patients with solid gastric tumor: Analysis of phase II studies of doxifluridine. Int J Oncol 17: 285-289, 2000.

19. Yang GW, Jiang JS and Lu WQ: Ferulic acid exerts anti-angiogenic and anti-tumor activity by targeting fibroblast growth factor receptor 1-mediated angiogenesis. Int J Mol Sci 16: 24011-24031, 2015.

20. Galluzzi L, Buqué A, Kepp O, Zitvogel L and Kroemer G: Immunological effects of conventional chemotherapy and targeted anticancer agents. Cancer Cell 28: 690-714, 2015.

21. Eichelberg C, Vervenne WL, De Santis M, Fischer von Weikersthal L, Goebell PJ, Lerchenmüller C, Zimmermann U, Bos MM, Freier W, Schirrmacher-Memmel S, et al: SWITCH: A randomised, sequential, open-label study to evaluate the efficacy and safety of sorafenib-sunitinib versus sunitinib-sorafenib in the treatment of metastatic renal cell cancer. Eur Urol 68: 837-847, 2015. 